\title{
EL PANTEÓN DE LOS REYES (SANTA MARÍA DE OVIEDO) \\ A TRAVÉS DE LA HISTORIOGRAFÍA \\ DE LOS SIGLOS XVI, XVII Y XVIII
}

\author{
Begoña Torre Miguel \\ Universidad de Oviedo \\ betomi89@hotmail.com
}

\section{Resumen}

La iglesia de Santa María del Rey Casto y su panteón real son mencionados con mucha asiduidad en la historiografía de todas las épocas, siendo de especial relevancia las referencias hechas en los siglos XVI, XVII y XVIII. De cada una de las fuentes se desprende una ideología concreta, ideología que ha contribuido a la elaboración de las diversas construcciones históricas y simbólicas de que ha sido dotada la iglesia funeraria ovetense. Como los lieux de memoire de Pierre Nora, la iglesia-panteón de Santa María del Rey Casto posee aún hoy una gran vitalidad simbólica.

\section{Palabras clave}

Panteón real, historiografía, vigencia simbólica, sarcófago de Ithacio.

\section{Abstract}

Santa Maria's church and the royal vault are constantly mentioned by historiography of all periods, but thesementions are specially relevant in the 16th, 17th and I8th centuries. A particular ideology is deduced from each source, and this has contributed to the development of different historical and symbolic constructions. Reminding Pierre Nora's concept of lieux de memoire, Santa Maria del Rey Casto has an unexpired symbolism.

\section{Keywords}

Royal vault, historiography, unexpired symbolism, Ithacio's sarcophagus. 


\section{INTRODUCCIÓN}

La iglesia-panteón ${ }^{\mathrm{I}}$ de Santa María del Rey Casto fue erigida a instancias del monarca Alfonso II (r. 79I-842) dentro del programa urbanizador desarrollado por éste con el que buscaba hacer de la nueva urbs regia de Oviedo la digna capital del Asturorum Regnum (Ruiz de la Peña Solar, 2000, pp. 67-92). Así, Oviedo llegó a consolidarse como una "auténtica ciudad sacra", siendo el templo funerario de Santa María "el centro neurálgico entre la catedral, San Vicente y San Pelayo", así como el núcleo del culto a la memoria regia (Carrero Santamaría, 2007, p. 383).

Es precisamente la función memorial de Santa María del Rey Casto lo que ha hecho de ella un edificio singular a la luz de la historiografía, que la ha provisto de diferentes significados según las épocas. Ni siquiera la absoluta reforma del edificio en el siglo XVIII (Madrid Álvarez, I990, 1998 y 20I0) trajo consigo la disminución de su significación simbólica. Por el contrario, contribuyó a la potenciación del interés de los historiadores por el templo, debido, entre otras cosas,a la pérdida total de la construcción altomedieval ${ }^{2}$ (Figs. I-3) en un momento en que empezaba a dotarse de valor artístico a este tipo de arquitectura, bautizada por Jovellanos como "asturiana" (Barón Thaidigsmann, 1985).

Esta vigencia memorial y simbólica de la iglesia-panteón, en la que aún hoy se sigue recordando cada año a Alfonso II a través de una misa con responso (Ruiz Tilve, 20I4), hace que podamos situarla en el contexto de los "lugares de la memoria" definidos por Pierre Nora en los que la realidad histórica y la simbólica confluyen (Nora, 1998). En efecto, son los propios restos materiales reinterpretados los que refuerzan el simbolismo de cualquier lugar memorial. De este modo, el paso del tiempo ha traído consigo en algunos casos una serie de "reapropiaciones y readaptaciones" de los elementos materiales, que pasan a convertirse en una prueba visual que corrobora las construcciones historiográficas y que adquieren

Su función funeraria ha sido objeto de debate historiográfico. César García de Castro, siguiendo la línea marcada por Aurelio de Llano, considera el panteón como una construcción posterior a la iglesia, aunque todavía dentro del reinado de Alfonso II. Por el contrario, y siendo esta la tesis más coherente, Isidro Bango Torviso y Eduardo Carrero Santamaría estiman que el templo fue concebido desde el principio como una construcción contraabsidada, y por lo tanto como una iglesia de carácter funerario (Bango Torviso, I992, pp.93-I32; Carrero Santamaría, 2003, p.35; 2007, p. 383; García de Castro, 1999, p. 36).

${ }^{2}$ Sólo se conserva el llamado sarcófago de Ithacio, que aunque data del siglo V se cree sito en la iglesia de Santa María desde tiempos de la monarquía asturiana. Sí se tiene la certeza, sin embargo, de que lleva en dicho templo desde el siglo xvI, habiendo recogido Ambrosio de Morales una rica descripción sobre el mismo (Fernández Fernández, I98I; Morales, I977, pp.87-90). 
así especial relevancia. De esta forma, como en la iglesia-panteón de Santa María del Rey Casto, el pasado continúa viviendo en el presente (Alonso Álvarez, en prensa).

Con este propósito, se analizan en este artículo las diferentes construcciones historiográficas y simbólicas de que se ha ido dotando a la iglesia-panteón de Santa María del Rey Casto dentro de un marco cronológico limitado. De este modo, se estudia aquí la historiografía de los siglos XVI, XVII y XVIII, por tratarse de testimonios decisivos a la hora de conocer el aspecto altomedieval del templo y del panteón, así como de su transformación posterior a principios del siglo XviII. Sin embargo, la importancia de la historiografía romántica y moderna no ha de olvidarse, pues han sido Fortunato de Selgas y Aurelio de Llano, entre otros, quienes han aportado más luz al estudio de este templo. Es por este motivo por el que la historiografía decimonónica será tratada de manera independiente en estudios posteriores.

\section{LA HISTORIOGRAFÍA ENTRE LOS SIGLOS XVI Y XVII}

Richard L. Kagan distingue dos conceptos historiográficos fundamentales: la "historia pro patria" y la "historia pro persona", siendo el primero el más habitual a partir del siglo XVI (Kagan, 20IO, pp. I4I-I7I). El origen de esta tendencia historiográfica se remonta a las "historias generales" salidas del taller historiográfico de Alfonso X, en las que comenzó a emplearse el castellano en detrimento del latín y en las que se proyectó una visión de España como unidad territorial, convirtiéndose la historia en una herramienta al servicio del poder, ${ }^{3}$ que como en el reinado de los Reyes Católicos, poseía un fuerte componente de exaltación regia. De este modo, las "historias pro patria", mediante el recurso al providencialismo

${ }^{3}$ Hay que tener en cuenta que la utilización ideológica de la historia ya es anterior a las crónicas alfonsinas, pues ya las Crónicas asturianas, las obras del obispo Pelayo de Oviedo, la Crónica de Sampiro, así como las obras de Lucas de Tuy y Rodrigo Jiménez de Rada muestran esta tendencia. Sin embargo son los textos salidos del taller de Alfonso X los que sientan las bases de las "historias generales" retomadas en el siglo XVI, con el empleo del castellano y la amplia visión del territorio espańol (Kagan, 20ıo, pp. 49-56). Con respecto al concepto de "territorio español" hay que tener muy en cuenta que la realidad medieval de España hay que entenderla no desde el punto de vista político, sino desde el punto de vista geográfico y territorial, con la idea siempre presente de la recuperación del territorio perdido tras la invasión musulmana como elemento de cohesión ideológica (Ladero Quesada, 2005, pp. 17-39). 
y al goticismo (Ríos Saloma, 2003, p. 383) contribuían a la legitimación de Isabel la Católica como reina, dando lugar a una "historia pro persona".

En esta línea, el rey Carlos V, soberano de un vastísimo territorio, no se interesó demasiado por una crónica general de su reino, sino más bien por una historia personal que destacara sus hazañas como monarca de un gran imperio. Sin embargo, con Felipe II se retoma la elaboración de una "historia general" de Espańa, pues el monarca, a diferencia de su padre, estaba poco interesado en crónicas sobre su persona o biografías. Es pues durante su reinado cuando van a escribirse "las primeras historias de España" (Cuart Moner, 20Iо, p. IIo), siendo la primera la de Esteban de Garibay y Zamalloa, publicada en Amberes por Plantin en I57I y titulada Los XL libros d'el compendio historial de las chrónicas y universal historia de todos los reynos de España. En este caso, ya nos encontramos ante una historia amplia y omnicomprensiva, que comienza con Túbaly finaliza con la conquista de Granada por los Reyes Católicos. De este modo, se crea "una historia común que no sólo ayudaría a los españoles a definirse frente a los miembros de otras naciones, sino que además les proporcionaría una herencia alrededor de la cual podían mantenerse unidos" (Kagan, 20I0, p. I69). En este sentido, hay que recordar nuevamente la complejidad de la realidad de Espańa, que aun en el siglo xvi posee un fuerte sustrato ideológico medieval en el que se combinan la "identidad común española" con las "singularidades de reino, región o grupo" (Ladero Quesada, 2005, p. 26). En este contexto, Garibay, a pesar de la pluralidad de España, articula su relato mediante la yuxtaposición de las historias de los diferentes territorios que la constituyen, llegando incluso a destinar un apartado a los reyes musulmanes de España, lo que indica que no identificó la Península con "el antiguo solar de los hispani", sino con "los reinos peninsulares que cuando escribió la obra estaban bajo la soberanía del Felipe II” (Cuart Moner, 20I0, p. III). Además de la obra de Garibay y en la misma línea de "historia general", nos encontramos con la obra del jesuita Juan de Mariana, publicada en I592 y titulada del mismo modo que la obra de Jiménez de Rada, Historia de rebus Hispaniae, traducida por él mismo al castellano pocos años después (publicada en I60I) con la finalidad de facilitar su difusión. La historia finaliza, al igual que la de Garibay, con la conquista de Granada, aunque con posterioridad, bajo los reinados de Felipe III y Felipe IV, fue puesta al día, llegando a incluir un resumen que abarca de I5I6 a I62I. Aunque a diferencia de Garibay no fue cronista real, sí mantuvo contactos con Felipe II y sus sucesores, quienes le apoyaron económicamente para ampliar su obra. Por otra parte, aunque no puede considerársele un verdadero investigador, sí fue un gran erudito que nos ofrece una historia ordenada y coherente de España. 
La importancia de las obras de Mariana y Garibay fue tal, que siguieron vigentes durante todo el siglo XVII, no habiendo "nuevos intentos de hacer una historia general hasta el siglo XviII" (Ríos Saloma, 2005, p. 389), más allá de la persistencia de los nombramientos de cronistas reales que van a encargarse sobre todo de llevar a cabo una historia política con fines eminentemente propagandísticos, auspiciada por los validos de Felipe III y Felipe IV, el duque de Lerma y el conde-duque de Olivares, respectivamente.

3. SANTA MARÍA DEL REY CASTO Y EL PANTEÓN REAL A TRAVÉS DE LA HISTORIOGRAFÍA DE LOS SIGLOS XVI Y XVII

Habiendo esbozado en los párrafos precedentes el marco ideológico e historiográfico que caracteriza a los siglos XVI y XVII, información sin la que resultarían incomprensibles y carentes de contexto las referencias de los autores modernos al periodo altomedieval asturiano, han de destacarse a este respecto cuatro figuras fundamentales, por ser quienes aportan los más valiosos datos acerca de la iglesia de Santa María de Oviedo. Estos son: Ambrosio de Morales, Tirso de Avilés, Luis Alfonso de Carvallo y Alfonso Marañón de Espinosa. Con diferentes cargos y por distintos motivos, los cuatro repararon en las construcciones altomedievales ovetenses, ofreciendo una descripción muy detallada en la mayoría de los casos, con la intención común de "aportar timbres de gloria o justificación de privilegios" (García de Castro, I995, p. 35).

\section{I. Ambrosio de Morales, cronista real de Felipe II}

Ambrosio de Morales fue nombrado cronista real ad honorem, esto es, sin percibir ninguna remuneración por el cargo, en el año $1563 .{ }^{4}$ No es de extrañar que Felipe II aceptara la solicitud hecha por Morales para ocupar dicho puesto, pues se trataba de un reputado erudito que había obtenido la Cátedra de Retórica en la Universidad de Alcalá de Henares hacia el año $1550,{ }^{5}$ lugar en el que se encontraba ejerciendo de maestro. La erudición y el interés por la historia de Ambrosio de

${ }^{4}$ Sin embargo, de manera excepcional Richard L. Kagan habla del año I569 (Kagan, 20Io, p. I6I).

'No está muy clara esa cronología. Se cree, en todo caso, que fue poco antes de 1550 (Sánchez Madrid, 2002, p. 55). 
Morales no es casual, sino que el ambiente en el que nació y se crió, propició su intensa formación, que hizo de él uno de los más importantes intelectuales del momento. Así, nace en Córdoba en I5I3 fruto del matrimonio entre Antonio de Morales y Mencía de Oliva, ambos de acomodada y cultivada familia. Su padre, aunque era médico de profesión, no limitaba sus intereses a la medicina, sino que poseía profundos conocimientos humanísticos que le llevaron a ser nombrado, en 1508 por el Cardenal Cisneros, catedrático de la recién fundada universidad de Alcalá de Henares. Además, su madre era hija de Fernán Pérez de Oliva, bachiller y geógrafo. Asimismo, el hermano de Mencía, y por lo tanto, tío de Ambrosio de Morales, llamado también Fernán Pérez de Oliva fue un hombre muy culto, que desempeñó el cargo de Catedrático de la Universidad de Salamanca, y que jugó un papel fundamental en la formación de su sobrino. Por otra parte, además de sus favorables circunstancias familiares, hay que tener en cuenta que en este momento en la ciudad de Córdoba se respiraba un "ambiente de inquietud cultural y espiritual”, favorecido por la incesante actividad de historiadores a lo largo de todas las épocas, sobre todo en época califal, lo que hizo de Córdoba un "notable foco de cultura humanística” (Ortiz Juárez, 1977, p. 6). Además de la inclinación histórica de Ambrosio de Morales, hay que destacar su fuerte vocación religiosa, que le lleva a profesar en la orden de San Jerónimo en I533, orden que habrá de abandonar posteriormente por motivos que no vienen al caso aquí (Sánchez Madrid, 2002, pp. 53-54); de cualquier modo, mantendrá su fervor religioso a lo largo de toda la vida, vínculo que le une también al creyente monarca Felipe II.

Sin duda alguna, su empresa historiográfica más importante mientras desempeñó el cargo de cronista real es la elaboración de la "Crónica general de España", obra que comienza en el lugar que fue dejada por el precedente cronista real y amigo suyo, Florián de Ocampo. ${ }^{6}$ De este modo, el estudio de Morales abarcaba desde el año 2 Io a. C. hasta el final del reinado de Vermudo III, fallecido en I037. Respetó incluso la numeración, comenzando de este modo en el libro VI y finalizando en el XII. El primer libro fue publicado en I574, y los últimos cinco en 1587.

A pesar de la importancia capital de la "Crónica" de Morales, que no fue la única labor que le encomendó el monarca, aunque sí la más importante, convie-

${ }^{6}$ Florián de Ocampo es nombrado cronista real bajo el reinado de Carlos V, en I539. En este momento Morales ya contemplaba la posibilidad de escribir una Historia de España y solicitar para ello el favor real, pero la amistad con Ocampo hizo que desechara esta opción, respetando así su puesto. En cualquier caso, es sabido que Morales no compartía el modo de hacer historia de su amigo, a quien reprochaba no ser lo suficientemente riguroso y basarse en datos fabulosos (Sánchez Madrid, 2002, p. 58). 
ne centrarse ahora en uno de los "viajes literarios" efectuados por el cronista a petición de Felipe II, concretamente el realizado por León, Galicia y Asturias en el año 1572, con el fin de inspeccionar las reliquias, libros y panteones reales que allí se encontraban para elaborar un informe de todo ello, así como valorar qué reliquias podían ser trasladadas al Escorial. Estos "viajes literarios" responden al interés de Felipe II por la documentación a través de nuevas fuentes de la historia sagrada, sobre todo en lo referente a la conversión de Espańa al cristianismo (Kagan, 20I0, pp. I62-163). Por otra parte, el hecho de que el rey solicite al cronista información acerca de los panteones reales es bastante significativo, en tanto supone la continuidad del interés de los monarcas por legitimar su poder haciéndose sucesores de los primeros reyes de España, ${ }^{7}$ como es el caso de los asturianos, que a su vez se consideraban herederos legítimos de los reyes visigodos, y todo ello siempre dotado en las diferentes épocas de un cariz religioso, en ese contexto de la pérdida y recuperación de España (Ríos Saloma, 2008, p. 205).

Así, este "viaje literario" por las tierras del norte de Espańa fue recogido en la obra que lleva por título Viage de Ambrosio de Morales por orden del rey D. Phelipe II a los Reynos de León, y Galicia, y Principado de Asturias para reconocer las Reliquias de Santos, Sepulcros Reales, y Libros manuscritos de las Cathedrales, y Monasterios, publicado dos siglos más tarde, en I765, por el padre Enrique Flórez. En ella, Ambrosio de Morales nos ofrece una detallada descripción de todo lo que observa en su viaje y, en relación al edificio que nos atańe, la iglesia de Santa María de Oviedo y su Panteón Real, la información que nos ofrece es valiosísima, fundamentalmente por no conservarse en la actualidad la construcción altomedieval que Ambrosio de Morales sí tuvo la oportunidad de conocer. El cronista explica pormenorizadamente la ubicación y el aspecto del edificio, el cual

es grande como de cien pies de largo y convenible ancho, repartido en tres Naves con buena proporcion, y cada Nave tiene seis claros de arcos muy semejantes en los postes, y vueltas, y en toda la cantería, y en pocas molduras, à los claustros de los arcos que ya estan hechos en el Real Monasterio de S. Lorenzo, aunque estos son mucho mas altos. El Altar mayor, y sus dos Colaterales tienen ricos marmoles, y muy grandes à la entrada, y allá dentro para formar las bóvedas a los rincones hay otros menores, mas muy ricos, y son todos doce. La advocación es de Nuestra Señora, y los dos Altares Colaterales de S. Julian y S. Estevan, como también algo desto se halla en nuestras historias. Toda la fabrica de las tres Capillas es de Godos, y mucho mas los arcos de la entrada harto semejantes à los de S. Roman de Hornija, y à los de Vamba, enterramientos de los Reyes Godos (...) Solas las

7 "y queriendo allende de esto tener noticia de los cuerpos de los Cuerpos de los Reyes nuestros antecesores (...)" (Morales, 1977, p. 2). La cursiva es mía. 
tres Capillas son de bóveda, y todo lo demás de la Iglesia es una mala teja vana, que parece no acabó el Casto aquello, según está pobre. El suelo de la Iglesia es de la misma argamasa que la Camara Santa. (Morales, 1977, p. 87)

Este fragmento transcrito de su obra deja patente el detallismo de Ambrosio de Morales a la hora de describir. A través de sus palabras, se percibe un edificio de tres naves, con cabecera triple abovedada, mientras que el resto de la edificación lleva cubierta de madera, lo que nos permite concluir que su aspecto era semejante al de cualquiera de las construcciones prerrománicas de la época de Alfonso II. Por otra parte, resultan enormemente interesantes, además, las comparaciones con las construcciones visigodas, sobre todo por el desconocimiento que en la actualidad se posee sobre los enterramientos reales de dicho periodo.

A continuación el cronista pasa a ocuparse de todos los enterramientos ubicados en el templo, comenzando por los situados en el cuerpo de la iglesia, muchos de ellos con atribuciones erróneas como bien señala el editor de la obra, Enrique Flórez (Morales, 1977, pp. 87-88). Seguidamente describe el panteón real, ubicado a los pies del templo, y de unas dimensiones muy reducidas. En este sentido, Ambrosio de Morales señala que es

una Capilla tan chica, que no tiene más de doce pies en largo, y ancho lo que es la nave mayor, y el techo es bagito, y hollado encima. Toda esta Capilla esta llena de sepulcros de Reyes, poco altos del suelo, tan juntos uno con otro que no se puede andar en la Capilla, sino sobre ellos, por lo qual la tienen siempre cerrada, sin abrirse mas que à personas que es razon. (Morales, 1977, pp. 88-89)

Inmediatamente después, Ambrosio de Morales comienza a describir cada uno de los sepulcros, que adscribe a los diferentes monarcas asturianos, llevando a cabo una importante labor epigráfica que, aunque ha recibido críticas en la actualidad por su falta de rigor en algunos casos (Abascal Palazón, 20I2, pp. 395-4I4), constituye un ámbito en el que el cronista ha destacado mucho y ha desempeñado una ardua labor de recogida de inscripciones. En el Panteón Real de Oviedo, Morales describe un total de siete sepulturas, ${ }^{8}$ asignadas cuatro de ellas, gracias a las inscripciones, a Alfonso II, Alfonso III, Ordońo I y Ramiro I. Las tres restantes presentan problemas a la hora de adscribirlas al nombre de un monarca, debido a la ausencia de nombres o mal estado de conservación de las

${ }^{8}$ Además de otras tres pequeñas sepulturas, probablemente pertenecientes a Infantes. Describe todas ellas como testigo ocular y recoge los epitafios (Morales, I977, pp. 89-9I). 
inscripciones. Una de esas sepulturas es el llamado "sarcófago de Ithacio" (Figs. 4 y 5), único vestigio de la época altomedieval que aún se conserva en la actualidad en el nuevo Panteón Real. De él, Ambrosio de Morales dice lo siguiente:

Al lado izquierdo deste [del de Alfonso II] está otro sepulcro mas levantado, y de mármol, con labores por todo el, de follages harto buenos, y por lo alto de la tumba van estos dos versos de buena letra:

\section{Inclusit tenerum praetioso marmore corpus}

Aeternam in sedem nominis Itatij

A los pies tiene levantada otra piedra en alto, donde está retratada la Cruz del Rey D. Pelayo, que llaman, de quien en la Camara Santa se ha dicho, y es perpetua insignia del Rey D. Alonso el Magno, como parece en la Fortaleza, y en una Fuente que el labró fuera de la Ciudad, y en otras partes. Conforme à esto, creo yo cierto que esta sepultura es de la Reyna D. Gimena, mujer de este Rey, que muriendo antes que el Rey su marido, el le hizo hacer tan rica sepultura, y el Artifice, como se usaba entonces, puso su nombre en tan rica obra, y el decir tenerum corpus, muestra como es de mujer. Y el Obispo D. Lucas de Tuy refiere como estos des Reyes marido, y mujer, fueron trasladados de Astorga à aquí. (Morales, 1977, pp. 89-90)

De este modo, Ambrosio de Morales considera que este sarcófago sirvió de sepultura a la esposa de Alfonso III, dońa Jimena, y que el nombre de Ithacio se corresponde con el artífice. El error es absoluto, y ya apreciado por el editor de su obra, el Padre Enrique Flórez, quien niega rotundamente la afirmación de Morales por distintos motivos: por el fallecimiento previo del monarca, quien enterrado en Astorga no pudo encargar este para su mujer; por la presencia del nombre de Ithacio en la inscripción de la tapa, que de ningún modo puede referirse al artífice, sino al finado. Además de estos acertados argumentos de Flórez, a partir del siglo xix la historiografía ha ido aportando algo más de luz al asunto (Quadrado, I855; Selgas, I908; Llano, 1928; Schlunk 1947, 1947b y 1978). En cualquier caso, se trata de una pieza de compleja identificación debido a la falta de documentación, pero la epigrafía, la decoración escultórica y los datos historiográficos hacen posible la extracción de algunas conclusiones que permiten un su mejor conocimiento, así como una aproximación a su datación. ${ }^{9}$

${ }^{9}$ Uno de los últimos estudios al respecto ha sacado a la luz la procedencia del mármol de la tapa: la ciudad portuguesa de Estremoz (Vidal y García-Cantero, en prensa). 
Como se ha podido comprobar, las descripciones de Ambrosio de Morales constituyen un testimonio histórico valiosísimo, debido a su detallismo y a su modo de concebir la historia como una actividad humanística, y, por lo tanto, rigurosa. Además, Morales puede ser considerado como un "hombre del Renacimiento", debido a su gran erudición. En cualquier caso, si algo hay que reprocharle es la falta de habilidad en la redacción, así como el excesivo patriotismo, algo habitual, por otra parte, que le llevó a no ser suficientemente crítico ante algunas informaciones, como, por ejemplo, "los mitos que rodeaban la presencia de Santiago en España” (Kagan, 20I0, p. I65) de no haber sido así quizás “su obra sería perfecta para su tiempo" (Sánchez Alonso, I944, II, p. 30).

\section{2. "Historia local": Tirso de Avilés y Luis Alfonso de Carvallo}

Retomando el concepto de Richard L. Kagan de "historia local", que también llama "corografía" (Kagan, 200I, pp. I30 y ss.) considero que resulta apropiada la inclusión en este apartado de los dos importantes eruditos asturianos de época moderna, como son Tirso de Avilés y Luis Alfonso de Carvallo. La "corografía" se identifica con la "historia local" y como tal, se desarrolla al margen de la "historia real”, esto es, la historia oficial, elaborada por los cronistas del rey. Además, la "corografía" permite realzar la historia de otras ciudades y regiones, que son apartadas de la historia espańola cultivada en los ámbitos oficiales. En cuanto a los autores de estas obras, son, generalmente, eruditos nativos de la población que es objeto de la historia, sobre la que escriben por un cierto "orgullo local" o para "conservar su memoria" (Kagan, 200I, p. I40). Por otra parte, en estas "historias locales" se presta mucha atención a las genealogías de la nobleza de la región, lo que ha de ser visto como una manera de dotar del espacio histórico del que carecían en la historia oficial los dirigentes municipales.

Por estos motivos se puede considerar, primeramente, a Tirso de Avilés como un "corógrafo"; su biografía resulta un tanto oscura. En cualquier caso, debió de nacer casi con seguridad en Oviedo en el ańo 1537 , ${ }^{10}$ fruto del matrimonio entre Gaspar de Avilés y Catalina Alonso de Hevia. En I548 se sabe que ya es canónigo de la catedral, y desde ese momento va a desempeñar muchos cargos en el cabildo, llegando a convertirse en una persona de notable influencia e importancia

Io Esta fecha es aportada y bien justificada por José Argüelles Martínez en su obra biográfica sobre Tirso de Avilés, lo que descarta las fechas dadas anteriormente que retrasaban su nacimiento a I516/I7 (Argüelles Martínez, I999). 
tanto personal como intelectualmente. En este sentido, hay que señalar su labor como archivero del cabildo de la catedral, lo que le permitió el acceso a una gran cantidad de documentación, y, además, resulta interesante la donación que hizo de un retablo, que ubicado en otro lugar y conservado en parte, aún se puede ver en la actualidad en la girola de la catedral. ${ }^{\text {II }}$ Finalmente, a Tirso de Avilés le sobrevino la muerte en el año 1598, año en que la peste asolaba la ciudad, aunque no parece que este haya sido el motivo de su fallecimiento (Argüelles Martínez, I999, pp. 63 y ss.). Tras su defunción, fue enterrado en la capilla de Santa Catalina de la catedral de $\mathrm{Oviedo}^{\mathrm{I} 2}$ y sus bienes fueron vendidos entre los miembros de la catedral, incluidos los manuscritos de sus obras, de los que probablemente se apoderaron compañeros del canónigo interesados en la historia, como Marańón de Espinosa, de quien se tendrá la oportunidad de hablar aquí.

Es en este contexto, por lo tanto, en el que hay que ubicar su obra Armas y linajes de Asturias y Antigüedades del Principado, la cual está dividida en dos partes bien diferenciadas ya en el propio título: la primera está dedicada a los escudos de relevantes familias de la nobleza asturiana y la segunda a la historia y restos materiales de épocas precedentes, sobre todo la Antigüedad y la Alta Edad Media. Obviamente, es esta segunda parte la que aquí resulta interesante. En lo relativo a la iglesia de Santa María de Oviedo y su Panteón Real, la información aportada por Tirso es bastante escasa, limitándose a decir de ella que es "una de las más antiguas iglesias que hai en la dicha ciudad de Oviedo" y que fue mandada hacer por el "Rey Dn. Alonso el Casto, a honra de Nuestra Señora y de los Doce Apóstoles” (Avilés, I99I, p. 176). Queda patente que se trata de una referencia brevísima que nada tiene que ver con la pormenorizada descripción de Morales. Más adelante, sí hace referencia Tirso de Avilés de manera más detallada al "sarcófago de Ithacio", aunque la información aportada resulta un tanto confusa. Parece que considera dicho sarcófago como la eterna morada de Alfonso III, argumento que fundamenta en la representación de la Cruz de la Victoria, representación que no es tal, pues se trata en realidad del crismón, símbolo cristiano, cayendo, de este modo, en el mismo error que Ambrosio de Morales.

${ }^{\text {II }}$ Además, se encuentra representado el propio Tirso de Avilés en dicho retablo (Argüelles Martinez, I999, pp. 67 y ss.; Gómez-Tabanera, I991, pp. 9 y ss.; Arca Miguélez, I997; Ramallo Asensio, 1985, pp. 467-472).

${ }^{12}$ La donación del retablo por parte de Tirso de Avilés está relacionado con su enterramiento, pues en el escrito de dicha donación incluía algunas condiciones, siendo la principal el poder enterrarse en la capilla de Santa Catalina (Caso, I98I, pp. 322-323). Sin embargo, su familia se encuentra enterrada en la capilla de San Andrés del convento dominico de Nuestra Señora del Rosario de Oviedo (García Cuetos, 200I). 
Además, la transcripción epigráfica es errónea, ya que transcribe IN DUCI, en lugar de INCLUSI. A pesar de todo, su testimonio no deja de ser valioso, sobre todo en este caso, en el que la escasa información acerca de la primitiva iglesia y su panteón hace que toda referencia, aun siendo breve y errónea, sea importante, pues el mero hecho de haber sido objeto de mención, así como los errores cometidos, contribuyen al mejor conocimiento de la edificación y de la visión que se tenía de ella en el siglo xvi.

Seguidamente, se ha de considerar aquí la aportación de Luis Alfonso de Carvallo, que nace en Cangas de Tineo (actualmente Cangas de Narcea) en I57I, donde vive los primeros años de su vida y estudia su carrera eclesiástica, hasta que a principios del siglo XviI se traslada a Oviedo, donde está documentado que ya en I6I3 ejerce como rector del Colegio de San Gregorio y profesor de Humanidades de la Universidad (Porqueras Mayo, 1996, pp. I6-17). En el año I6ı6 se traslada a Monforte de Lemos, donde ingresa en la Compañía de Jesús, a la que pertenecerá toda su vida, dedicándose a la enseñanza, hasta su fallecimiento en 1635. Desde su ingreso Carvallo nunca más residirá en Asturias, desarrollando su actividad en colegios jesuíticos de distintas ciudades, siendo la primera la localidad gallega mencionada de Monforte, seguida de Monterrey, Logroño, León, Segovia y Villagarcía de Campos, donde fallece. Es en este contexto en el que tenemos que ubicar su obra Antiguedades y cosas memorables del Principado de Asturias, que se publicará póstumamente en $1695 .{ }^{13}$

Los datos aportados por Carvallo sobre la iglesia de Santa María y el Panteón de los Reyes son minuciosos, permitiendo, al igual que la descripción de Morales, hacerse una idea bastante aproximada de su apariencia. Así, detalla el aspecto del templo, y en el Panteón se detiene de manera especial, señalando su ubicación "en lo postrero de la Iglesia, enfrente del Altar mayor", y se refiere a ella, más que como una capilla, como una "cueva", lo que da cuenta de las pequeñas dimensiones y la modestia del recinto. En este sentido, señala lo siguiente:

El techo es muy baxo, de madera, sin labor ninguno, y sirve de suelo a un aposento que esta encima, como Tribuna, ò Coro de la Iglesia: tiene azia la Capilla mayor unas puertas de red de hierro à lo antiguo, y una pequeña ventana, por donde entra bien poca luz, con lo qual està muy lobrega la pieça: el suelo està todo lleno de sepulturas de Reyes antiguas,

${ }^{13}$ El asunto de su tardía publicación es bien tratado por Alberto Porqueras Mayo en su biografía sobre Carvallo y según apunta el autor, tal retraso en la publicación de la obra parece no haberse debido a la censura de la Inquisición, sino a la censura interna de la propia Compañía de Jesús (Porqueras Mayo, 1996, pp. 36-40). 
y altas del suelo cosa de dos pies, y tan llegadas unas à otras, que no se puede andar sino por encima de ellas. (Carvallo, I977, p I80)

Se trata, sin duda alguna de una riquísima descripción, que, como ha podido comprobarse, coincide con la de Morales. A continuación, Carvallo refiere lo siguiente:

Bendita humildad, y verdadero desengaño de la vanidad del mundo, en que estos gloriosos Reyes tanto florecieron, que nos dexaron en los monumentos de sus muertos huessos tan vivo exemplo de modestia, aviendo tenido tanto animo, y esfuerço para aumentar y engrandecer las cosas de la Religion Christiana. (Carvallo, I977, p. I80)

En escasas líneas alaba Carvallo la humildad y la sencillez de la iglesia-panteón, en un claro acto de exaltación regia y religiosa, siendo ambos aspectos muy habituales en este siglo XviI y en la línea de lo que Kagan ha llamado "historia pro patria" e "historia pro persona", términos de los que ya se ha tenido la ocasión de hablar.

Es en lo referente al "sarcófago de Ithacio", por otra parte, donde las opiniones de Morales y Carvallo son opuestas, rebatiendo Carvallo abiertamente la información que había aportado el cronista de Felipe II. Así, bajo el subtítulo de "Un Epitafio mal entendido en Oviedo" Carvallo señala:

Entre la sepultura de Alfonso el Magno, y el Casto, está otra sepultura con este Epitafio:

\section{Inclusit tenerum precioso marmore corpus}

Aeternam in sedem nominis Itatij

Piensan algunos [obviamente se refiere a Ambrosio de Morales] que esta es la sepultura de la Reyna Doña Ximena, interpretandolo de esta manera: El Artifice llamado Itacio encerrò en este precioso mármol, para perpetua morada, el delicado cuerpo; y no me parece buena interpretación, porque no es buena Gramatica suplir supuesto de tercera persona, sin aver alguna dependencia de donde se pueda colegir; ni aquel genitivo podía ponerse sin nombre que le rigiesse; ni el nombre corpus està bien sin que se declare cuyo es; y và contra toda costumbre de Epitafios poner el nombre del Cantero, y dexar el de la persona sepultada; ni el Cantero avia de hazer tan buen dístico, y si otro lo hazia, no avia de meter en èl el nombre del Cantero, ni los versos muestran aver sido de persona que no supiesse muy bien Latin. Tampoco la Reyna quando murió era de tierno cuerpo, sino de mucha edad; y quando fue traida a Oviedo, serian los huesos, y no cuerpo tierno, como dice el letrero. Lo que à mi me parece, que pues sus huessos fueron traìdos con los de su marido, estarán juntos en la sepultura del Magno, y que esta otra sepultura es de un Infante chiquito, y moçuelo de pocos años; y que donde dize inclusit, avia de decir inclusum, 
ò inclusum est; y assi dirà: El cuerpo tierno del que se nombrava Iracio, fue enterrado en este precioso mármol, para morada perpetua. (Carvallo, 1977, pp. 180-255)

Realmente la opinión de Carvallo es mucho más acertada que la de Morales. En su explicación, no sólo muestra un profundo conocimiento del latín, sino que aporta motivos muy razonables de otra naturaleza, como lo son la imposibilidad de que aparezca en una sepultura el nombre del artífice y no el del finado, así como la probabilidad de que en dicho sarcófago se encuentren los restos de "un infante chiquito", aunque como demuestran las grandes dimensiones del sarcófago esto último parece poco probable. Además, y lo más importante, estas consideraciones con respecto a esta pieza, así como la semejanza de la descripción de la iglesia con la aportada por Morales, demuestran cómo Carvallo manejó la obra del cronista real para la elaboración de sus Antigüedades y cosas memorables del Principado.

\subsection{Alfonso Marañón de Espinosa y su Historia eclesiástica de Asturias}

Aunque la información aportada por quien fuera primer rector de la Universidad de Oviedo sobre la iglesia-panteón de Santa María de Oviedo es limitada, el detallismo y las peculiaridades de su descripción, así como la propia importancia del autor como uno de los grandes intelectuales del siglo XvII, hace imposible que pueda prescindirse de su aportación. ${ }^{14}$ Por un lado, el autor hace constantes referencias a otras fuentes, lo que demuestra un gran afán de rigor, muy en consonancia con los ideales humanistas. De este modo alude a Ambrosio de Morales, pero también cita a Don Rodrigo Jiménez de Rada, el ya mencionado autor autor de la Historia de rebus Hispaniae, así como algunos documentos, por ejemplo, el "Libro Gótico de las Donaciones". ${ }^{\text {I5 }}$ En este sentido, resulta curioso que habiendo formado parte del cabildo catedralicio y conociendo por lo tanto a Tirso de Avilés, no le mencione en ningún momento, al igual que Avilés tampoco lo hizo (Abol-Brasón y Álvarez Tamargo, 1977, p. 199).

${ }^{14}$ Para una biografía de Marañón de Espinosa y detalles sobre su obra Historia eclesiástica de Asturias vid. Abol-Brasón y Álvarez Tamargo, 1997, pp. 159-209; Rivas Andrés, 1977, pp. XV-XXV. Conviene aclarar, por otra parte, que este autor ha sido tratado en un epígrafe independiente por haber sido considerado más conveniente, pues aunque fue una figura de máxima importancia en el ámbito asturiano, no nació en dicho territorio y por lo tanto su obra no encaja dentro de las denominadas "historias locales" (Kagan, 200I, pp. I30 y ss.).

${ }^{\text {is }}$ El Liber Testamentorum del obispo Pelayo. 
Pues bien, de la iglesia señala su ubicación, en la "parte setentrional" de la catedral y apunta que fue mandada hacer por Alfonso II, quien dentro de ella "edificó otra capilla para entierro suyo y de sus sucesores" (Marañón de Espinosa, 1977, p. 30). No aporta, sin embargo, nada acerca de sus dimensiones ni su aspecto. Sí enumera los enterramientos que se encuentran en el Panteón, identificando la tumba de Alfonso III con el conservado "sarcófago de Ithacio". Esta identificación viene motivada por la misma razón que en los casos anteriores, esto es, la confusión del crismón representado en la tapa del sarcófago con la Cruz de la Victoria. Además, identifica el nombre de Ithacio con el del artífice, lo que demuestra su dependencia de la obra de Morales. ${ }^{16}$ Menciona también, tomando como fuente al obispo Pelayo, el traslado de cuerpos de León a Oviedo en época de Vermudo II debido al temor a las razias de Almanzor, señalando que "pasado el peligro y vuelto Almanzor, volvieron a León los cuerpos de los reyes y dejaron los de los santos" ${ }^{17}$ Finalmente, termina la referencia a este edificio con la descripción detallada del Calvario, del que hoy se conservan las cabezas de bulto redondo (los cuerpos estaban pintados), y el suelo, que parece causarle enorme curiosidad debido al amplio párrafo que le dedica.

De este modo, puede concluirse que Ambrosio de Morales es quien aporta la más rica y detallada información, seguido de Luis Alfonso de Carvallo, más riguroso y claro en su exposición. Por su parte, Tirso de Avilés apenas incluye datos a este respecto; y, finalmente, Marañón de Espinosa, sin ser tan detallado como Morales y Carvallo, elabora una historia más precisa y rigurosa en la que abundan las referencias a otras fuentes.

\section{LA HISTORIOGRAFÍA DE LA ILUSTRACIÓN: EL SIGLO XVIII}

El inicio del siglo XVIII español está marcado por el fallecimiento del último rey Habsburgo, Carlos II, que muere precisamente en el año i700. Esto tiene como consecuencia el comienzo de una guerra sucesoria que durará hasta la firma del Tratado de Utrecht en I713, acuerdo que permite a Felipe V de Borbón conservar el trono de Espańa, que ya por testamento le había dejado el último rey de la Casa de Austria. En este contexto de agitación e inestabilidad con que se inaugu-

${ }^{16}$ Resulta curioso que no haya manejado la obra de Carvallo, aunque la explicación parece evidente: esta fue publicada póstumamente en I695, y Marañón de Espinosa falleció en I62I.

${ }^{17}$ Los cuerpos de los santos son el de San Vicente, San Claudio y San Pelayo (Marańón de Espinosa, I977, p. 3I). 
ra el nuevo siglo es en el que brotan las ideas ilustradas, cuya transmisión se vio facilitada por el acceso al trono del monarca francés ${ }^{18}$, aunque, en cualquier caso, España era terreno abonado para la recepción y asimilación de dichas ideas. En este sentido, a partir de 1670 emerge paulatinamente el grupo de los llamados novatores, un

grupo de eruditos laxamente relacionados entre sí que relacionaban las dificultades económicas y políticas de España con el fracaso de sus conciudadanos a la hora de incorporar los nuevos modos de pensamiento científico y filosófico vinculados a las luminarias intelectuales tales como Bacon, Grocio y Descartes. (Kagan, 20IO, p. 356)

Una de sus preocupaciones fundamentales era acabar con todos los mitos históricos que habían sido divulgados a partir de los "falsos cronicones", de gran difusión durante todo el siglo xviı español. Estos textos eran de carácter providencialista y, por ello, estaban respaldados por el clero y la Monarquía, ${ }^{20}$ de modo que refutarlos iba a constituir una tarea difícil, aunque los novatores estaban dispuestos a afrontarla. La figura central del grupo era Gaspar Ibáńez de Segovia, marqués de Mondéjar, y era en su casa donde los novatores tenían sus tertulias en las que trataban sobre la necesidad de una historia más crítica y veraz. El propio marqués de Mondéjar publicó algunas obras en las que atacaba de manera directa los "falsos cronicones", pudiendo ser considerada su obra como "uno de los primeros intentos de historia crítica en España y uno de los ejemplos más tempranos de un pensamiento ilustrado" (Ríos Saloma, 2005, p. 392).

Las tertulias organizadas alrededor de la figura del marqués de Mondéjar no fueron más que el origen de una actividad intelectual que se prolongó en el tiempo. Así, hacia 1735 la tertulia se organizaba en torno a Julián de Hermosilla y era denominada Academia Universal, aunque más tarde pasaron a llamarla Academia de la Historia. Esto culminó con la creación de la Real Academia de la Historia en 1738 por parte de Felipe V, fundada a petición de estos tertulianos organizados

${ }^{18}$ La llegada de Felipe V va a facilitar la divulgación de las filosofías de la historia (Rousseau, Kant y Voltaire, sobre todo) y de los precursores de la historia crítica (Richard Simon o Dom Mabillon) (Bourdé y Martin, 2004, pp. 7I-IO2).

19 "El fin justificaba el medio; los fraudes piadosos, el dolo pio, estaban admitidos en la moral corriente cuando tenían por objeto un motivo de edificación; y no faltaban escritores de autoridad que defendiesen que era lícito falsear la historia cuando el honor ó el interés de la patria lo exigían" (Godoy Alcántara, 1999, pp. I5-16).

${ }^{20}$ Richard L. Kagan se refiere a esta tendencia difundida por las crónicas falsas como "nacionalismo piadoso". Los mitos tenían que ver con temas como los plomos de Sacromonte o la llegada de Santiago a España, entre otros (Kagan, 20io, pp. 358 y ss.). 
en torno a Hermosilla. La principal pretensión de la Real Academia fue reescribir la historia de España, ${ }^{21}$ tratando de corregir todas las falsedades que habían sido divulgadas por los "falsos cronicones". En este sentido, una de sus primeras labores fue compilar un Diccionario histórico-crítico de España, concebido como una suerte de enciclopedia histórica basada en Le grand dictionaire historique de Luis Moréri y el Dictionaire historique et critique de Peter Bayle. Además, la Academia promovió la creación de una publicación periódica, Fastos de la Real Academia, iniciativa que fracasó por motivos económicos cuando apenas se habían publicado tres números. Sin embargo, los académicos emplearon otros mecanismos para difundir sus ideas, siendo muy relevante el papel de las conferencias, impartidas por los propios académicos.

Como se ha podido comprobar, todas las actividades de la Real Academia fueron encaminadas a la elaboración de un nuevo tipo de historia, una historia que debía responder al principio ilustrado por excelencia, la razón. Para los ilustrados la libertad era "su alma, la libertad bajo la forma más sana de todo lo que se designa con ese vocablo, la libertad de hacer un uso público de la razón” (Hazard, I985, p. 39. La cursiva es mía); he ahí la función de la historia como herramienta didáctica cuyo estudio permitiría un mayor conocimiento de la naturaleza humana y, por consiguiente, unas reformas sociales que llevarían al progreso. Así, puede decirse que "la conciencia del 'tiempo moderno' condujo durante el siglo XviII a una 'historia universal"” que "llenó la nueva representación racionalista del tiempo y de la historia con los contenidos laicos de la idea de progreso", y aunque el proceso histórico seguía siendo concebido de manera teleológica,

los agentes del progreso eran ahora la razón y la ilustración humanas, encarnadas en el absolutismo moderno (Voltaire), o en la nación-estado gobernada por el derecho (Hume) o en la sociedad comercial de la civilización europea (Smith, Turgot). (Ruiz Torres, I99293, p. 154)

Con esta finalidad de elaborar una historia veraz que respondiese a los ideales políticos ilustrados la Academia organizó viajes, "equivalentes a las misiones arqueológicas actuales”, por distintos lugares de España para que se explorasen los archivos y los documentos conservados en ellos. ${ }^{22}$ Así puede afirmarse que

${ }^{21}$ El primer estatuto de la Real Academia de la Historia reclamaba "purificar y limpiar la [historia] de nuestra España de las fábulas que la deslucen, e ilustrarla de las noticias que parezcan más provechosas” (García Hernán, 2004, p. 170).

${ }^{22}$ Un precedente indudable de estos "viajes literarios" es Ambrosio de Morales (Kagan, 20IO, p. 388). 
la historiografía dieciochista comprende distintos conceptos de historia; por un lado, la "historia crítica", basada en la búsqueda de la verdad y cuyo fin último es corregir los errores del pasado (falsas crónicas), por lo que no supone cambios de contenido sino que es un enfoque meramente metodológico. Por otro lado, comprende también una "historia civil", término con el que los ilustrados se referían a "una historia total que abarque toda la realidad temporal que pretende estudiar", y por lo tanto, directamente relacionada con la "historia nacional", que responde a la idea de nación ilustrada y a esa "conciencia de comunidad, de interna y recíproca vinculación". Se trata también de una "historia filosófica" en tanto siempre se buscan las causas y los efectos (Chacón Delgado, 2007, pp. I87-2II).

Puede concluirse, por lo tanto, que la Ilustración pretendía una historia crítica y filosófica en cuanto a su método, y nacional en cuanto a su contenido. El interés por la historia nacional implicó, "desde los supuestos epistemológicos de que parte el siglo XviII (...) remontarse al conocimiento de su raíz originaria” (Maravall, 1972, p. 273). Esta atención prestada a los orígenes de la nación supuso volver la mirada hacia el pasado visigodo y altomedieval. En este sentido, se producen una serie de novedades conceptuales, entre las que destaca la noción de "arquitectura asturiana ${ }^{23}$ con la que Jovellanos se refiere a los edificios altomedievales de su región natal, aspecto en el que se profundizará en obras posteriores. Pero esta no es la única aportación conceptual interesante de la historiografía dieciochista, sino que también aparece por primera vez el término "reconquista". Fue José Ortiz y Sanz quien en su obra de siete volúmenes titulada Compendio cronológico de la Historia de España (I795-1803) usó este concepto. Parece poco probable que su utilización se haya debido simplemente a la búsqueda azarosa por parte del autor de un sinónimo de "restauración", ${ }^{24}$ sino que el uso de la noción de "reconquista" estaría más bien "relacionada con una nueva forma de interpretar la lucha contra el Islam basada (...) en las nuevas circunstancias históricas, políticas y culturales del momento en el que Ortiz escribe" (Ríos Saloma, 2005, p. 400). Además de la

${ }^{23}$ Jovellanos acuña dicho concepto en $\mathbf{1 7 8 8}$, con su obra Elogio de don Ventura Rodríguez, aunque las peculiaridades de la "arquitectura asturiana" ya habían llamado su atención durante su estancia en Asturias en I782, y así se lo hace saber a Antonio Ponz en una de sus cartas (Barón Thaidigsman, 1985, p. I09).

${ }^{24}$ Señala Martín F. Ríos Saloma (2005, p. 399) que el término “restauración” se utiliza desde la Edad Media, aspecto que conviene matizar. Hay que tener en cuenta que "la notion de restauration est ainsi au coeur de la visión astur-léonaise du monde, alors qu'il faut attendre au plus tôt 1063, dans une copie des actes du concile de Jaca, pour qu'apparaisse pour la première fois en Aragon le terme recuperare". Puede ser entendido el término como "rétablir les institutions" o "renouver avec le passe" (Deswarte, 2003, pp. 303-315). 
aparición de nuevos conceptos, fue tendencia habitual en la historiografía ilustrada la rectificación de fechas, realizadas en base a documentos históricos. Esta preocupación por las dataciones da lugar a obras bajo el título de "compendio cronológico" o "sinopsis cronológica", del tipo de la señalada más arriba de Ortiz y Sanz. Un importante ejemplo de esta tendencia lo constituye una de las obras del ya conocido marqués de Mondéjar, que lleva por título Examen chronologico del año en que entraron los moros en España y en la que se establece la fecha de 7II como ańo de la invasión musulmana, rechazando la que hasta entonces se había considerado válida, el 7I4 (Ríos Saloma, 2005, p. 392-393).

A pesar del fuerte espíritu crítico con el que los ilustrados abordaron la historia, la que se desarrolló en el seno de la Real Academia fue más bien una "historia erudita”, esto es, una historia fiel a los documentos y también crítica, pero sólo hasta cierto punto, ya que algunas verdades oficiales no llegaron a rebatirse, continuando de alguna manera la historia "subordinada a la teología y a la historia eclesiástica” (Chacón Delgado, 2007, p. 193). ${ }^{25}$

5. SANTA MARÍA DEL REY CASTO Y EL PANTEÓN REAL A TRAVÉS DE LA HISTORIOGRAFÍA DEL SIGLO XVIII

La coherente selección de autores que han referido en sus obras noticias acerca de la construcción que nos ocupa no constituye en este periodo una tarea sencilla, pues en el siglo XviII hay una gran pluralidad de escritos acerca del pasado medieval español, si bien es cierto que no todos hacen referencia al Oviedo altomedieval. En cualquier caso, se van a incluir aquí sólo los autores cuyos testimonios he considerado más relevantes. ${ }^{26}$ De este modo se analiza la obra de uno de los autores de la España Sagrada, Manuel Risco y la de Gaspar Melchor de Jovellanos, así como una breve mención a la interesante obra del padre Manuel Medrano. Siguiendo a César García de Castro, se ha dedicado el primer apartado a la denominada "corriente crítica", a la que se adscribe Risco, mientras queun

${ }^{25}$ Una de las figuras más críticas fue Gregorio Mayans, quien con más intensidad defendió la necesidad de la exactitud documental de la historia. No han de olvidarse tampoco a dos de las grandes figuras de la Ilustración española: Benito Jerónimo Feijoo y Pedro Rodríguez de Campomanes (García Hernán, 2004, pp. 127-I94).

${ }^{26}$ En aras de la brevedad no incluyo las menciones a Santa María del Rey Casto hechas por autores de la talla de Juan Agustín Ceán Bermúdez, Eugenio Llaguno, y Juan Francisco de Masdeu, por ser todas ellas muy escuetas. Vid. Llaguno, ı829; Masdeu, año M. DCC. XCI, tomo IX. 
segundo epígrafe se ha dedicado a la "corriente arqueologista", a la que se adscribe Jovellanos. Esto no significa que el ilustrado gijonés no haya sido crítico, pues como gran representante de la Ilustración española por supuesto que lo ha sido. Sin embargo, mostró un intenso interés "por los restos materiales del pasado, por su inserción geográfica, por la toponimia, por la recogida y transcripción de epígrafes... en suma por lo que hoy día cubre científicamente la Arqueología” (García de Castro, 1995, pp. 35-36). Finalmente, en un tercer apartado se hace referencia a la peculiar obra de Manuel Medrano.

\section{I. Corriente crítica: Manuel Risco}

Habiendo terminado el volumen veintinueve de la "España Sagrada", le sobrevino la muerte al padre agustino Enrique Flórez, iniciador de este gran compendio, el día 5 de mayo de I773, poniendo fin al "más notable esfuerzo de la investigación histórica del siglo XviII” (Campos y Fernández Sevilla, 2006, p. 29). Sin embargo, a los tres días de haber fallecido Flórez, el monarca Carlos III promulga una Real $\operatorname{Orden}^{27}$ por la que se le encarga la continuación de la obra a Manuel Risco, también religioso de la Orden de San Agustín. Aunque la obra va a ser continuada incluso después de la muerte del propio Risco, prolongándose hasta el siglo $\mathrm{xx}^{28}$ conviene centrarse en el inmediato sucesor de Flórez, por ser él el autor de los volúmenes referidos a Asturias. Del mismo modo que Enrique Flórez contó con un colaborador, Francisco Méndez, el padre Manuel Risco también contó con la ayuda de un compañero de la Orden, Antolín Merino, quien plasmó la biografía de su mentor en el prólogo al volumen XLIII de la España Sagrada (Ruiz de la Peña, I986, p. 5-I6). Así, es sabido que Manuel Risco nace en Haro el I de julio de I735, ciudad en la que estudia durante los primeros ańos, tomando el hábito de la Orden de San Agustín en 1752 en la iglesia de Nuestra Señora del Risco, en Ávila, motivo por el que toma el nombre por el que se conoce. ${ }^{29}$ A partir de este momento va a ampliar su formación cursando los estudios de Filosofía y Teología, materia esta última de la que será catedrático. Tras la muerte de Flórez en 1773

${ }^{27}$ Aunque el Is de abril de 1769 la Congregación de la Orden ya le había designado para continuar la España Sagrada (Sagredo Fernández, 1975, p. 532).

${ }^{28}$ Van a suceder a Risco, los agustinos Juan Fernando de Rojas, Antolín Merino y José La Canal. Continuado después por la Real Academia de la Historia. Vid. Sagredo Fernández, I975, pp. 532 y ss.

${ }_{29}$ Realmente su nombre y sus apellidos eran Juan Manuel Martínez Ugarte. Vid. Ruiz de la Peña, 1986, p. 5 . 
Risco tomó el relevo en la elaboración de la obra la España Sagrada, revisando, los dos últimos volúmenes de Flórez, el XXVIII y el XXIX. A partir de aquí, inicia la escritura del volumen XXX, llegando a escribir hasta el XLII, publicado en I8oI, el mismo año de su muerte. Para su realización "se atuvo a las normas fijadas por su antecesor en el rigor crítico de las indagaciones", llegando a veces incluso a contradecir al propio Flórez (Sánchez Alonso, 1950, III, p. 224), a lo que hay que sumar el enriquecimiento de los apéndices con nuevos hallazgos.

Manuel Risco dedica a Asturias tres volúmenes: el XXXVII, el XXXVIII y el XXXIX; y lo hace a petición de Jovellanos, quien no dejaba de esforzarse "para la recuperación del conocimiento cabal de la historia de Asturias" (Ruiz de la Peña, 1986, p. 9). El primero de estos volúmenes se publicó en Madrid en 1789 con el título de Antigüedades concernientes a la región de los Astures Transmontanos desde los tiempos mas remotos hasta el siglo X. Establecimiento del Reyno de Asturias y memorias de sus Reyes. Fundacion de la Iglesia de Oviedo: noticias de sus primeros Obispos y examen crítico de los Concilios Ovetenses. Precisamente este primer tomo de los dedicados a Asturias es el que resulta interesante aquí, por ser el que abarca hasta el siglo $\mathrm{x} .{ }^{30}$ En este sentido, en el capítulo XVIII, que lleva por título "Funda el rey Don Alonso la Iglesia de San Salvador de Oviedo", no sólo se refiere a ésta, sino a todas las construcciones promovidas por el casto monarca, a quien alaba por ello en varias ocasiones a lo largo del texto en un claro ejemplo de exaltación regia, por una parte, así como de su fuerte capacidad crítica, por otra, pues ya valora la arquitectura altomedieval asturiana. ${ }^{3 \mathrm{I}}$ Risco incluye en su relato, como no podía ser de otro modo, la iglesia de Santa María del Rey Casto y su real panteón. En primer lugar, la menciona, destacando sus tres altares, junto con el Salvador y San Tirso, y dice de las tres iglesias que fueron adornadas "con la mayor diligencia” y que Alfonso II "observó" en todas ellas y en su palacio "el mismo orden, que guardaron los Godos en Toledo" (Risco, 1986, p. 139). Un poco más adelante, le dedica unas breves líneas:

Edificó en honor de la Virgen María otra Iglesia pegada á la del Salvador por la parte del septentrión, erigiendo además del altar principal el de San Esteban en el lado derecho, y en el siniestro otro para memoria de San Julián. En la parte occidental del referido templo

${ }^{30}$ El siguiente tomo abarca del X al XIV, y el último del XIV al XVIII.

${ }^{31}$ "Los testimonios más excelentes de su religion ácia el culto divino y de su esmero en la hermosura de sus ciudades, quedaron en su Corte de Oviedo, donde hizo obras magnificas y admirables en aquel tiempo" (Risco, 1986, p. 139). 
del Salvador hizo una pieza para depositar en ella los cuerpos de los Reyes. (Risco, 1986, p. I40-I4I)

Nada más aporta Risco al respecto de la iglesia y su panteón. A lo que sí hace referencia en los distintos capítulos dedicados a cada monarca es a las sepulturas que estaban emplazadas en el Panteón Real. Sin embargo no alude en ningún momento al sarcófago de Ithacio ni se identifica con este sepulcro la eterna morada de ninguno de los monarcas. Este aspecto resulta verdaderamente curioso, dado que en este momento la iglesia de Santa María ya estaba completamente reformada y por lo tanto presentaba, en lo fundamental, el mismo aspecto que en la actualidad, por lo que el único sepulcro del que pudo ser testigo ocular fue del de Ithacio. Sin embargo, han de tenerse en cuenta una serie de aspectos. El primero y más importante es el seńalado por Juan Ignacio Ruiz de la Peńa, y es que es probable que escribiera este primer tomo sobre Asturias antes de desplazarse a la región, por lo que no habría conocido ninguna de las construcciones mencionadas in situ (Ruiz de la Peña, 1986, p. 13). En cualquier caso, hubo de leer sobre este sepulcro en otras obras, como la de Ambrosio de Morales, a quien menciona numerosas veces. En este sentido ha de tenerse en cuenta que la España Sagrada es una obra de historia eclesiástica, por lo que a Risco quizá no le interesó profundizar en algunos aspectos arqueológicos como lo es este vestigio de la monarquía astur. Además, del sarcófago de Ithacio sólo se tienen dudas, por lo que, independientemente de si fue testigo ocular del mismo o no, pudo omitirlo de manera consciente para no caer en hipótesis incomprobables y fabulaciones, en consonancia con la corriente crítica y el afán ilustrado por la búsqueda de la verdad.

5.2. Corriente arqueologista: Gaspar Melchor de Jovellanos y la "arquitectura asturiana"

Baltasar Melchor Gaspar María de Jovellanos nació el 5 de enero de 1744 en Gijón, en el seno de "una de las más antiguas familias de Asturias" (Varela, 1988, p. 16). Su favorable posición social le permitió materializar su patente interés por la historia, la sociedad y la cultura, entre otros ámbitos del conocimiento, erigiéndose como uno de los hombres ilustrados más relevantes del siglo XviII español. Así pues, posee una elevada producción de obras históricas, que puede dividirse, según indica Sánchez Albornoz, en tres periodos: el primero se corresponde con su etapa madrileña (I778-I790), en el que la historia le sirve de base 
para el sostenimiento de tesis generales; el segundo se corresponde con la etapa asturiana (I790-I80I), en el que empieza a considerar absolutamente necesaria la consulta de documentos históricos; y, por último, el periodo comprendido entre su destierro en Palma de Mallorca y su muerte (I80I-I808), en el que se reafirma en la consideración de la consulta documental como hecho indispensable (Baron Thaidigsmann, I985, p. 25). Como buen ilustrado, Jovellanos estimaba la visita a los archivos como tarea obligatoria, tarea que le resultaba tan agradable como tediosa en algunas ocasiones, y así se lo hizo saber a Masdeu en una misiva, en la que lo califica de "caro y fastidioso" (Barón Thaidigsmann, 1985, pp. 25-26).

Jovellanos siempre estuvo muy interesado en el arte, y esto queda patente en sus obras, de las que han de destacarse el Elogio a las Bellas Artes, el Elogio de don Ventura Rodríguez y las Cartas del Viaje de Asturias. Precisamente por su afición a las artes y el modo de abordar su estudio, puede ser considerado como un "prerromántico" (Arco, 1946, pp. 3I-32). En este sentido, siguió un método de trabajo muy concreto en el que pueden distinguirse tres pasos: el estudio de los documentos históricos, la descripción formal y la valoración artística, considerada como finalidad principal. La valoración artística consiste, en términos generales, en evaluar el "mérito" que posee esa obra dentro del proceso histórico. Por eso Jovellanos repara en periodos y obras que habían sido hasta entonces ignorados por la historiografía, con la intención de "restablecer su mérito ante la historia”. Así se sintió atraído por la época medieval, una atracción que se agudiza durante su viaje a Asturias en 1790 y, sobre todo, en la etapa de su destierro mallorquín. De la producción artística de la Edad Media va a interesarse por la arquitectura, hecho que responde a criterios estéticos ilustrados, relacionados con la verdad y la naturaleza. La arquitectura posee más independencia de esta última, pues aunque los materiales provienen de ella, el grado de imitación al que está sometida la arquitectura es menor que en otras artes. Por ello, mientras que la pintura y la escultura son más miméticas en sus representaciones, la arquitectura es más independiente de la naturaleza en tanto "no se esclaviza a sus formas". Así, para Jovellanos, aunque "su 'fuerte' fue la pintura", el antinaturalismo y falta de proporción de las figuras medievales le hicieron dotar de un valor superior a la arquitectura (Barón Thaidigsmann, 1985, pp. 26-28).

Es en este contexto en el que, en su obra Elogio de don Ventura Rodriguez, mencionó por primera vez el concepto de "arquitectura asturiana". Dicha noción comprende un ámbito cronológico que se extiende desde el siglo viII hasta finales del siglo XII. Como puede deducirse de esta limitación temporal, este concepto de Jovellanos englobaba no sólo la propia "arquitectura asturiana" sino también la arquitectura del románico, lo que muestra, por otra parte, que la acuñación de 
dicho término responde al origen del estilo y no a su extensión territorial, pues el concepto jovellanista abarcaba un ámbito geográfico que superaba los límites del Principado. Esta ambigüedad conceptual hace que en muchas ocasiones el propio Jovellanos no se atreva a calificar de "asturianos" algunos edificios románicos de gran importancia, como puede ser San Martín de Frómista (Barón Thaidigsmann, I985, p. I2I).

Además, en el mismo marco cronológico ubicó Jovellanos otra "especie" de arquitectura, la "arabesca", que tiene correspondencia con lo que hoy entendemos como arquitectura "mozárabe", ${ }^{2}$ término empleado por vez primera por Ceán Bermúdez. Va a ser precisamente el vínculo que establece Jovellanos entre la "arquitectura asturiana" y la "arquitectura arabesca" lo que va a permitir la individualización de la primera, al romper con la idea sostenida por Ponz y Ceán de "arquitectura asturiana" como degeneración de la romana y la goda (Barón Thaidigsmann, 1985, p. I22). Para el ilustrado gijonés, la "arquitectura asturiana" posee un "carácter" que

dista menos de la arquitectura árabe que de la gótica o tudesca, así como la árabe primitiva distaba menos de la griega. Esto me ha llevado a creer que los arquitectos de Asturias, empleados en las obras de alguna entidad por aquellos tiempos, eran árabes también, o al menos discípulos de los árabes. (Jovellanos, 198I, p. I28)

Por otra parte, ha de vincularse el interés de Jovellanos por la arquitectura medieval en general y la asturiana en particular con el ya mencionado espíritu prerromántico, por el que se buscan los orígenes de la nación a través de las obras arquitectónicas más peculiares para ser constituidas como símbolos de orgullo nacional. En este sentido, para Jovellanos, en la época altomedieval "resurgimiento monárquico, nacionalismo y religión cristiana" se encuentran "ejemplarmente unidos" (Barón Thaidigsmann, 1985, pp. III-II2). Esta vinculación entre arte y política, que se consolidará en el Romanticismo, y que convierte en símbolos de una nación ciertos estilos arquitectónicos, ha de ser relacionado, en última instancia, con los lieux de memoire y los "símbolos impuestos" y "símbolos construidos" definidos por Piere Nora (Nora, 1998, p. I0).

Sin embargo, a pesar del interés de Jovellanos en la "arquitectura asturiana" no llegó a llevar a cabo un estudio pormenorizado de sus edificios, habiendo sido

${ }^{32}$ A partir de la publicación de la obra de Manuel Gómez Moreno, Iglesias mozárabes (I919) se califica al arte del siglo x como "mozárabe". Sin embargo, se le han dado otras denominaciones, como "arte de la repoblación”, por Camón Aznar (Yarza, 2009, pp. 9I-I22). 
Llaguno quien aglutinó en su obra un mayor número de construcciones. Quizá esto se deba a la concepción, por parte del ilustrado gijonés, de la "arquitectura asturiana” como un todo, considerándola como un hecho histórico y explicándola, por lo tanto, en función de causas económicas, políticas y religiosas (Barón Thaidigsmann, 1985, pp. 136-I39). Aún así, las reflexiones de Jovellanos supusieron el inicio de la valoración del arte medieval, algo de por sí ya importante, a lo que si se suma el haber sucedido en un siglo como el xviII, cuyos gustos estéticos respondían al más absoluto clasicismo, resulta de una originalidad indudable.

\subsection{La carta cuarta del Viaje de Asturias: la catedral de Oviedo}

Es en su carta cuarta a Antonio Ponz en la que Jovellanos se refiere a la iglesiapanteón de Santa María del Rey Casto:

Pero la del rey Casto, sustituida a la antigua del mismo nombre, y costeada por el piadoso obispo don Juan Reluz a los principios del presente, es obra humilde, inventada sin gusto y trabajada sin delicadeza. Casi otro tanto se puede decir de las capillas de Santa Eulalia y Santa Bárbara (...). (Jovellanos, I98I, p. I3I)

De una alusión tan breve se desprende, sin embargo, una idea muy importante: el desprecio de los ilustrados por la arquitectura barroca. En ella sólo veían desorden y mal gusto; en palabras del propio Jovellanos, los edificios de fábrica barroca eran "edificios fanfarrones, donde la riqueza del ornato escondía la falta de orden y sistema, y deslumbraba al ignorante espectador"; incluso llega a hablar de "la nueva y pestilente doctrina borrominesca" (Arco, 1946, p. 60). Esto se debe a una visión orgánica del arte, que como todo en la naturaleza, posee siempre épocas de esplendor seguidas de otras de decadencia. Así, el barroco no había sido más que la degeneración del arte renacentista anterior, degeneración con la que había conseguido terminar el Neoclasicismo del siglo Xviır. ${ }^{33}$ Por otra parte, Jovellanos sustituye el nombre del obispo, Tomás Reluz, por el de Juan, un error sin demasiada relevancia.

${ }^{33}$ Conviene recordar que es justo a mediados de este siglo cuando la Estética se convierte en una doctrina filosófica, término acuńado por Baumgarten que publica su obra Aesthetica en I750. Es en este momento cuando surgen los debates sobre el concepto de belleza y Winckelmann ensalza la perfección del arte de la Antigüedad (clásico) (Marchán Fiz, I996, pp. I2-I3 y 66-7I). 
Seguidamente vuelve a referirse a la iglesia del Rey Casto, sin describir su aspecto primitivo, remitiendo al lector a la obra de Ambrosio de Morales si quiere conocerlo. Tampoco se detiene en la descripción de su aspecto actual, actitud que puede considerarse justificada por su opinión sobre el arte barroco. Por otro lado, le presta atención al panteón, aunque nuevamente no lo describe, pero sí recoge la inscripción en la que se señalan todos los reyes que yacen en él. ${ }^{34}$ Finalmente, parece que sintió enorme curiosidad por el sarcófago de Ithacio, único elemento de todo el templo al que le dedica una descripción:

En la misma capillita se ve también un sepulcro o arca de piedra de forma y escultura bien antigua, donde según la tradición, estuvo sepultado no sé qué infante. Lo que yo vi en uno de los frentes fue aquel célebre monograma griego del lábaro de Constantino, tan usado y tan conocido en la edad media, y que sin embargo equivocó Morales con la cruz de don Pelayo, quizá porque halló ésta muy repetida en los antiguos monumentos de Asturias. En la cubierta de esta arca se leen en buenas letras romanas estos dos versos:

\section{Inclusi tenerum praetioso marmore corpus}

Aeternam in sede nominis Ithacii.

(Jovellanos, 1981, p. 133)

El motivo por el que se detiene en esta excepcional pieza parece evidente: se trata del único vestigio antiguo del templo, y por lo tanto, el único verdaderamente interesante a los ojos de un ilustrado como Jovellanos. Por otra parte, reconoce por fin el asturiano la representación del monograma de Cristo, ${ }^{35}$ que tantas confusiones había suscitado a los historiógrafos anteriores, quienes lo confundían con la Cruz de la Victoria.

Puede concluirse que la aportación a la historiografía artística de Jovellanos es absolutamente excepcional, ya que, aunque sus afirmaciones no siempre son sostenibles debido a la dudosa autenticidad de las fuentes, mostró una gran "intuición histórica” que le permitió sacar conclusiones semejantes a las que sacaría un historiador actual. Además, conceptualizó e individualizó un estilo, el asturiano, término que aún hoy, aunque con unos límites diferentes, es empleado (Caso

${ }^{34}$ Comete errores en la transcripción, que le hacen considerar erróneamente la posibilidad de que el Panteón haya sido fundado por Vermudo I, en vez de por Alfonso II Vid. Jovellanos, I98I, p. I32.

${ }^{35}$ Aunque Jovellanos habla del "lábaro de Constantino", este no es más que el origen del monograma cristiano (García García, 20IO, pp. 2I-3I). 
González, I98I, p. 3I). De este modo Jovellanos, "en pleno prerromanticismo, acusa las tendencias, puestas de manifiesto ya en Europa, que cobrarán vigencia en el siglo XIX" (Moreno Alonso, 1979, p. 159).

\subsection{El padre Manuel Medrano}

Habría sido un error concluir este artículo sin mencionar la peculiar obra llevada a cabo por el padre dominico Manuel Medrano, obra que sin duda merecería un estudio independiente y minucioso. Con el título de Patrocinio de Nuestra Señora en España. Noticias de su imagen del Rey Casto y vida del Ilustrísimo Señor, el señor D. Fr. Thomas Reluz, fue publicada esta obra en 1719, y en ella describe el padre Medrano el templo y el panteón tanto en su aspecto original como en el actual, ya que su vida coincidió con el momento de transición de un edificio a otro. De este modo, el autor se deshace en halagos hacia el nuevo panteón, edificado "con tanta grandeza, y tantos primores, que a pesar de la evidencia de los ojos, no acaba de persuadirle el entendimiento, quepa en tan corto sitio, tanta perfeccion" (Medrano, I719, p. I82). En general, puede decirse que es una obra escrita en un lenguaje profuso y abigarrado, cuya finalidad es exaltar la figura del obispo Tomás Reluz, que es descrito como un hombre de una gran fe y como promotor de las artes, lo que permite al autor compararle con Alfonso II el Casto, dando lugar a fragmentos de texto realmente curiosos.

\section{CONCLUSIONES}

La iglesia de Santa María del Rey Casto y su panteón real, como construcciones históricas, siempre han respondido a unos intereses ideológicos que han ido cambiando a lo largo del tiempo. Por una parte, la historiografía de los siglos xvi y XVII muestra el empleo del templo y el panteón como elementos de exaltación regia, mientras que el siglo xviII supone el arranque de su concepción como un elemento de exaltación regionalista.

Asimismo, ha podido apreciarse cómo en los siglos XVI y XVII la producción histórica estuvo, generalmente, en manos de eruditos eclesiásticos, mientras que con la llegada de la Ilustración, la historia pasó a ser elaborada en su mayor parte por intelectuales civiles, que la dotaron de un tono más crítico. De este modo, hubo una evolución clara de la historia erudita a la historia crítica. 
Además es notable el cambio de gusto a lo largo de las diferentes épocas. En este sentido, el interés por la Edad Media fue creciendo a partir del siglo XviII, a la vez que se acentuaba el sentimiento nacional. Por otro lado, la visión del Barroco fue muy negativa, sometiendo a las construcciones de este estilo a duras críticas, como se ha podido ver en el caso de Santa María.

Finalmente, conviene resaltar el carácter documental de las fuentes anteriores al siglo xviII, como Ambrosio de Morales y Luis Alfonso de Carvallo, pues gracias a ellas nos es posible reconstruir el aspecto original de la iglesia y el panteón.

Como se ha podido ver, la iglesia de Santa María del Rey Casto y el panteón real han tenido diferentes significados simbólicos según las épocas, pero nunca han quedado relegados al olvido. Aún hoy, la iglesia y el panteón siguen recordando a Alfonso II, el Nuestro, en un contexto claramente regionalista, a través de una misa con responso celebrada cada año que muestra "la huella que dejó en esta ciudad, que es la suya" (Ruiz-Tilve, 20I4).

\section{BIBLIOGRAFÍA}

Abascal Palazón, Juan Manuel, 2012: "Ambrosio de Morales como informante epigráfico: un debate abierto", Velaia: Revista de prehistoria, historia antigua, arqueología y filología clásicas, no 29, 2012, 395-4I4.

Abol-Brasón, Álvarez Tamargo, Manuel, 1997: "Alfonso Marañón de Espinosa”, Asturianos Universales, vol. II, Madrid, pp. 159-209.

Alonso Álvarez, Raquel, 2007: "Los enterramientos de los reyes de León y Castilla hasta Sancho IV. Continuidad dinástica y memoria regia”, e-Spania, $\mathrm{n}^{\circ}$ 3, I-I5.

_ delos, intercambios y recepción artística: de las rutas maritimas a la navegación en red, vol. II, Universitat de les Illes Balears.

- 2007-2008: "Patria Ullata asperitate moncium. Pelayo de Oviedo, el archa de las reliquias y la creación de una topografía regia”, Locus Amoenus, 9.

_- en prensa: "The cruces gemmatae of Oviedo and their use in new liturgical and propagandistic contexts betweem the eleventh and twelfth centuries". En prensa.

Arca Miguélez, Ma Cristina, 1997: “Tirso de Avilés y Hevia”, Asturianos Universales, vol. XII, ed. Páramo, Madrid.

Arco, Ricardo del, 1946: “Jovellanos y las Bellas Artes”, en Revista de Ideas Estéticas, $\mathrm{n}^{\mathrm{o}} \mathrm{I}$, tomo IV (enero-febrero-marzo), CSIC, pp. 3I-64. 
Argüelles Martínez, José, 1999: Tirso de Avilés. Revisión biográfico-histórica en el cuarto centenario de su muerte, Grafinsa, Oviedo.

Arias Páramo, Lorenzo, 2007: Enciclopedia del Prerrománico en Asturias, vol. II, Fundación Santa María la Real, Aguilar de Campoo.

Avilés, Tirso de: Armas y linajes de Asturias y Antigüedades del Principado (ed. Grupo Editorial Asturiano, Oviedo, 199I).

Bango Torviso, Isidro G., I992: "El espacio para enterramientos privilegiados en la arquitectura medieval española”, Anuario del Departamento de Historia y Teoría del Arte, vol. IV.

Barón Thaidigsmann, Javier, 1985: Ideas de Jovellanos sobre arquitectura (arquitectura altomedieval), Servicio de Publicaciones del Principado de Asturias, Oviedo.

Guy Bourdé y Hervé Martin, Las escuelas históricas, Akal, Madrid, 2004 ( $\mathrm{I}^{\mathrm{a}}$ ed. I992).

Carrero Santamaría, Eduardo, 2003: El conjunto catedralicio de Oviedo durante la Edad Media, Real Instituto de Estudios Asturianos, Oviedo.

__ 2007: "La 'Ciudad Santa' de Oviedo, un conjunto de iglesias para la memoria del rey", Hortus Artium Medievalium, vol. II, nº I3.

Carvallo, Luis Alfonso de: Antigüedades y cosas memorables del Principado de Asturias (ed. Ayalga, Gijón, 1977).

Caso, Francisco de, 198I: La construcción de la Catedral de Oviedo (I293-I587), Universidad de Oviedo, Oviedo.

Caso González, J. M., 1981: Prólogo, Cartas del viaje de Asturias, Ayalga, Gijón, (vol. I).

Chacón Delgado, José, 2007: "El concepto de historia en España (I750-I850)", Araucaria. Revista Iberoamericana de Filosofía, Politica y Humanidades, ${ }^{\circ} 17$.

Cuart Moner, Baltasar, 2004: "La larga marcha de las historias de España en el siglo Xvi”, en La construcción de las historias de España, Ricardo García Cárcel (coord.), Fundación Carolina, Centro de Estudios Hispánicos e Iberoamericanos, Marcial Pons, Madrid, 45-I26.

Deswarte, Thomas, 2003: De la destruction à la restauration. L'idéologie du royaume d'Oviedo-Leon (VIII-XI siècles), Brepols, Turnhout, Belgium.

Fernández Fernández, Armando, 1981: "El sarcófago de Ithacio de la Catedral de Oviedo", Studium Ovetense, no 9 .

Gallego, Jose Andrés (coord.), 2003: Historia de la historiografía española, Encuentro, Madrid.

García de Castro Valdés, César, 1995: Arqueología cristiana de la Alta Edad Media en Asturias, Real Instituto de Estudios Asturianos, Oviedo. 
_- I999: "Las primeras fundaciones", en La catedral de Oviedo, vol. I, ed. Nobel, Oviedo.

García Cuetos, Ma Pilar, 200I: El convento dominico de Nuestra Señora del Rosario de Oviedo. Historia y arquitectura, Real Instituto de Estudios Asturianos, Oviedo.

García Fitz, Francisco, 2009: "La Reconquista: un estado de la cuestión", Clio \& Crimen, $\mathrm{n}^{\circ}$ 6, Centro de Historia del Crimen de Durango.

García García, Francisco de Asís, 2010: "El Crismón”, en Revista Digital de Iconografía Medieval, vol. II, no 3 .

García Hernán, Enrique, 2004: "Construcción de las historias de España en los siglos XVII y XVIII", en La construcción de las historias de España, Ricardo García Cárcel (coord.), Fundación Carolina, Centro de Estudios Hispánicos e Iberoamericanos, Marcial Pons, Madrid, pp. I27-I94.

—_, 2006: "La España de los cronistas reales en los siglos Xvi y Xvı", Norba, Revista de Historia, Instituto de Historia, CSIC, vol. I9, I25-I5O.

Gil Fernández, Juan, Moralejo, Jose L., y Ruiz de la Peña Solar, J. Ignacio, I985: Crónicas asturianas, Universidad de Oviedo.

Godoy Alcántara, José, 1999: Historia crítica de los falsos cronicones (I868) Universidad de Granada.

Hazard, Paul, 1985: El pensamiento europeo en el siglo XVIII, Alianza, Madrid (I ${ }^{\text {a }}$ ed. en "Revista de Occidente", 1946).

Herr, Richard, I979: España y la Revolución del siglo XVIII, Aguilar, Madrid. Jovellanos, Gaspar Melchor de, Cartas del viaje de Asturias, ed. J. M. Caso González, Ayalga, Gijón, 198I (vol. I).

Kagan, Richard L., 200I: "Clío y la Corona: escribir historia en la España de los Austrias", España y el mundo atlántico, Homenaje a John H. Elliot, Richard L. Kagan y Geoffrey Parker (eds.), Marcial Pons, Ed. de Historia, Madrid.

- 2010: Los Cronistas y la Corona. La política de la Historia de España en las Edades Media y Moderna, Centro de Estudios Europa Hispánica y Marcial Pons Historia, Madrid.

Ladero Quesada, Miguel Ángel, 2005: "Unidad y diversidad en la España Medieval. En torno a las ideas de nación, patria y estado", en Fundamentos medievales de los particularismos hispánicos, IX Congreso de Estudios Medievales (2003), Fundación Sánchez Albornoz, Ávila.

Llaguno, Eugenio, I829: Noticias de los arquitectos y arquitectura de España, Madrid.

Llano, Aurelio de, I928: Bellezas de Asturias de Oriente a Occidente, Oviedo. 
Madrid Álvarez, Vidal de la, I990: "La construcción de la Capilla de Nuestra Señora del Rey Casto y Panteón Real de la Catedral de Oviedo", Liño, no 9.

__ 1998: "Reformas barrocas en los panteones reales españoles: el Panteón Real de la catedral de Oviedo y el Panteón de los Reyes de San Isidoro de León", Scripta, Homenaje a Élida García García, II, Universidad de Oviedo.

_ - 20I0: "La Capilla Real de la Catedral de Oviedo, Felipe V y la Virgen de las Batallas. La creación de un instrumento de legitimación borbónica", La catedral guia mental y Espiritual de la Europa Barroca, Universidad de Murcia.

Marañón de Espinosa, Alfonso, 1977: Historia eclesiástica de Asturias, ed. de Victoriano Rivas Andrés, Monumenta Historica Asturiensia, Gijón.

Maravall, Jose Antonio, 1972: "Mentalidad burguesa e idea de Historia en el siglo XVIII", Revista de Occidente (segunda época), tomo XXXVI, no I07, $250-286$.

Marchán Fiz, Simón, 1996:La estética en la cultura moderna, Alianza, Madrid (I ${ }^{\mathrm{a}}$ ed. 1987).

Masdeu, Juan Francisco: "España Goda", en Historia crítica de España y de la cultura española, tomo IX, editado en Madrid, imprenta de Sancha, año M. DCC. XCI.

Medrano, Manuel, I719: Patrocinio de Nuestra Señora en España. Noticias de su imagen del Rey Casto y vida del Ilustrísimo Señor, el señor D. Fr. Thomas Reluz, Oviedo.

Morales, Ambrosio de, 1977: Viaje a los reinos de León, y Galicia, y Principado de Asturias, Oviedo.

Moreno Alonso, Manuel, 1979: Historiografía romántica española. Introducción al estudio de la historia en el siglo XIX, Universidad de Sevilla.

Nora, Pierre, 1998: Realms of memory, vol. III, Columbia University Press.

Porqueras Mayo, Alberto, 1996: Estudios sobre la vida y la obra de Luis Alfonso de Carvallo (I57I-I635), Real Instituto de Estudios Asturianos, Oviedo.

Quadrado, Jose Ma, 1977: Recuerdos y Bellezas de España. Asturias y León (I877) Madrid, Ayalga.

Ramallo Asensio, Germán, 1985: Escultura barroca en Asturias, Instituto de Estudios Asturianos, Oviedo.

Rios Saloma, Martín F., 2005: "De la Restauración a la Reconquista: la construcción de un mito nacional (Una revisión historiográfica. Siglos XVI y XVII)", En la España medieval, Universidad Complutense de Madrid, 28, 379-4I4.

—_, 2008: "La Reconquista: génesis de un mito historiográfico", Historia y Grafia, no 30, I9I-2I6. 
Risco, Manuel, 1986: "Antigüedades concernientes á la región de los Astures Transmontanos desde los tiempos mas remotos hasta el siglo x", en España Sagrada, tomo XXXVII, Madrid, oficina de Blas Roman (ed. facsímil: Mases, Gijón, 1986).

Rivas Andrés, Victoriano, 1977: "Presentación", Historia Eclesiástica de Asturias, Monumenta Historica Asturiensia, Gijón, pp. XV-XXV.

Ruiz de la Peña Solar, J. Ignacio, I986: "Prólogo", Espańa Sagrada, tomo XXXVII, Madrid, pp. V-XVI.

—, 2000: La monarquía asturiana (7I8-9I0), Cangas de Onís.

Ruiz-Tilve, Carmen: " 27 de marzo y otras fechas. El origen del nombre de la plaza de la Escandalera, el éxito de la gala de los Premios Líricos y la misa por Alfonso II", en La Nueva España, Oviedo, 06.04.2014.

Sagredo Fernández, Félix, 1975: "Enrique Flórez (1702-1773) y su España Sagrada", Homenaje a don Agustín Millares Carlo, tomo I, Caja Insular de Gran Canaria.

Sánchez Alonso, Benito, 1944 y 1950 : Historia de la historiografía española, vol. II y III, Madrid.

Sánchez Madrid, Sebastián, 2002: Arqueología y Humanismo. Ambrosio de Morales, Universidad de Córdoba.

Schlunk, Helmut, 1947: “Arte visigodo" y "Arte asturiano", Ars Hispaniae, vol. II, Plus-Ultra, Madrid.

__ I947b: Schlunk, Helmut, "El sarcófago de Castiliscar y los sarcófagos paleocristianos españoles de la primera mitad del siglo Iv", Revista Príncipe de Viana, $\mathrm{n}^{\circ} 28$, pp. 305 y ss.

Schlunk, Helmut, y Hauschild, Theodor, 1978: Hispania Antiqua. Die Denkmäler der frühchristlichen und westgotischen zeit, Verlag Philipp von Zabern, Mainz am Rhein.

Selgas Albuerne, Fortunato de, 1908: Monumentos ovetenses del siglo IX, Madrid. Varela, Javier, I988: Jovellanos, Alianza, Madrid.

Vidal, Sergio y García-Cantero, Virginia "The use of Estremoz marble in Late Antique sculpture of Hispania: new data from the petrographic and cathodoluminescence analyses", ASMOSIA X, 20I2, en prensa.

Yarza, Joaquín, 2009: Arte y arquitectura en España, 500-I250, Cátedra, Madrid. 

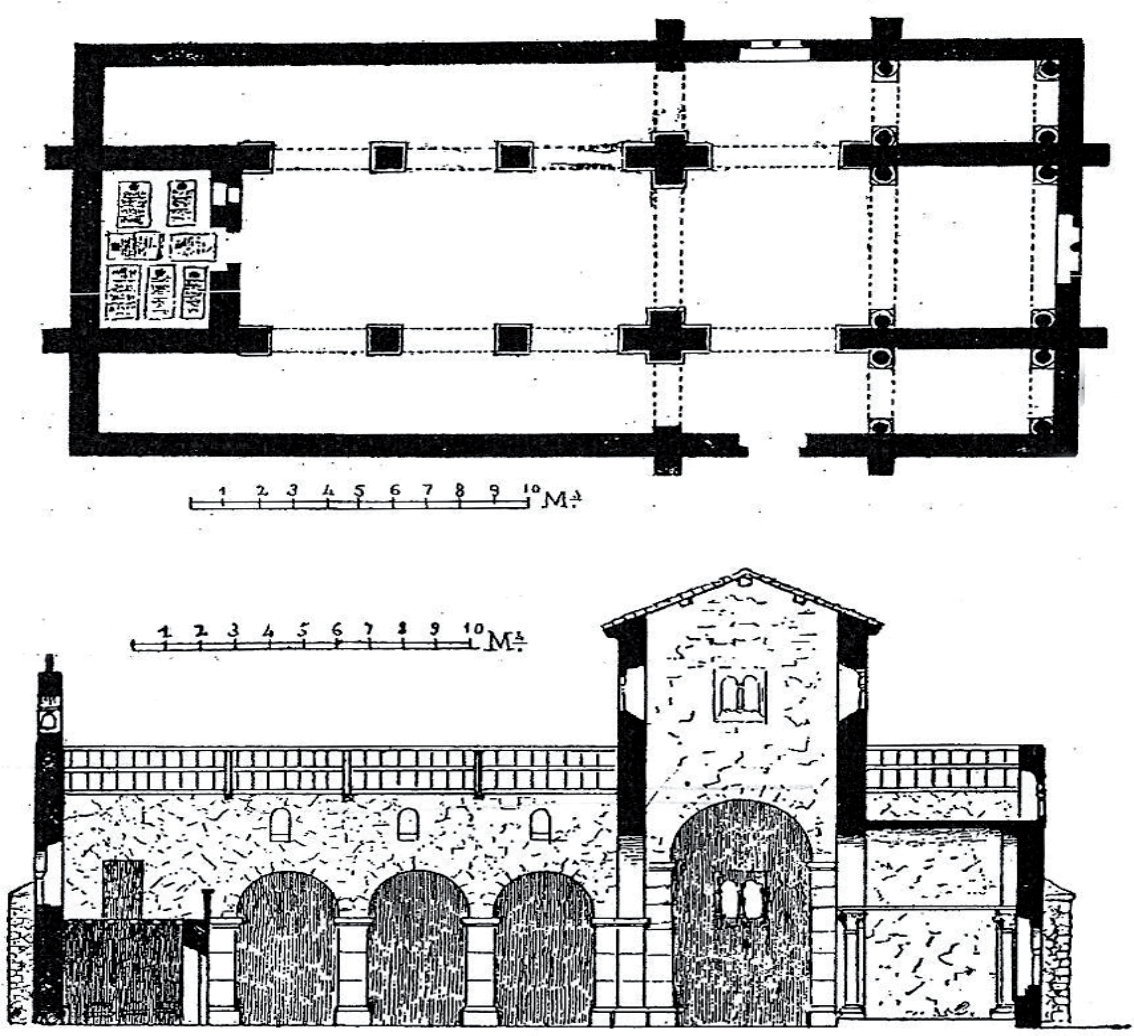

Fig. I. Planta y alzado de la iglesia de Santa María del Rey Casto, según Fortunato de Selgas (Monumentos ovetenses del siglo IX, p. 73) 


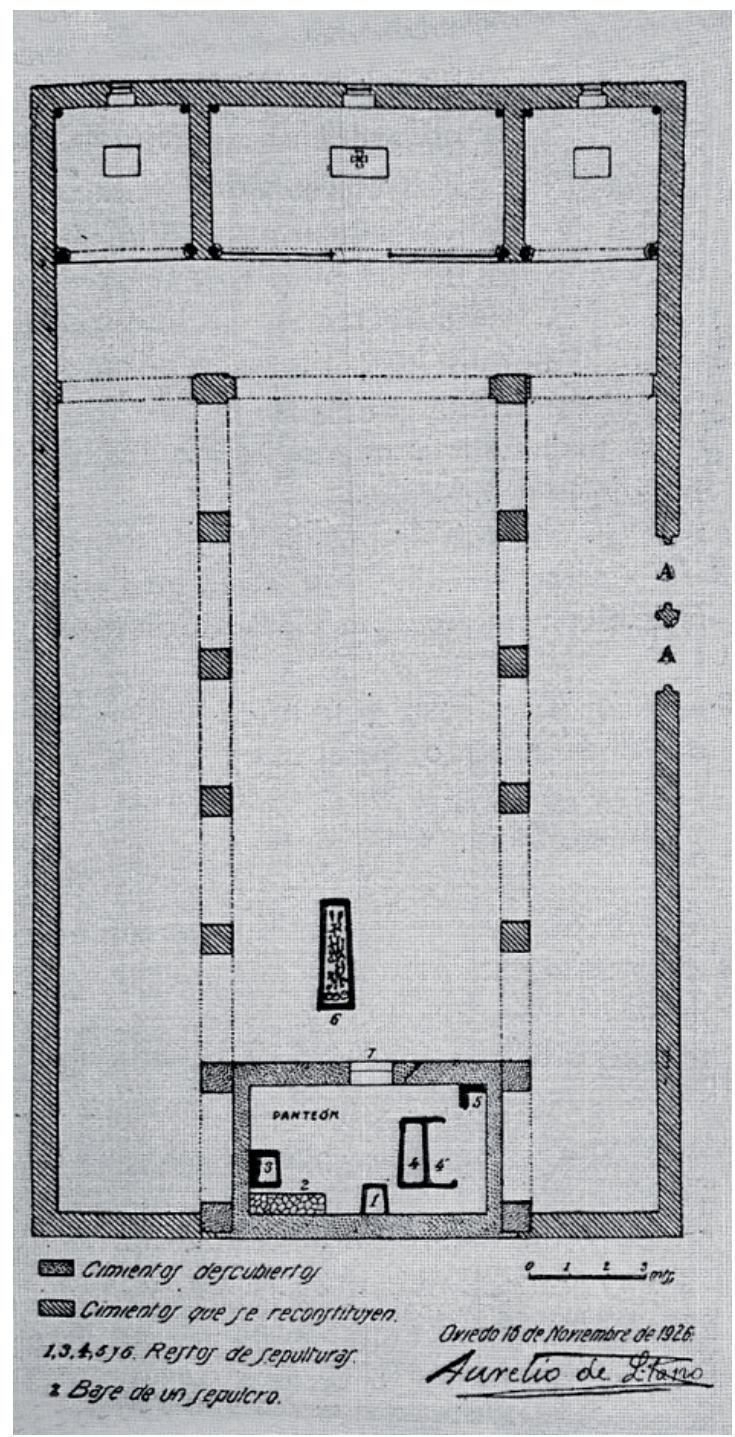

Fig. 2. Planta de la iglesia de Santa María del Rey Casto, según Aurelio de Llano (Bellezas de Asturias. De oriente a occidente, p. 337). 


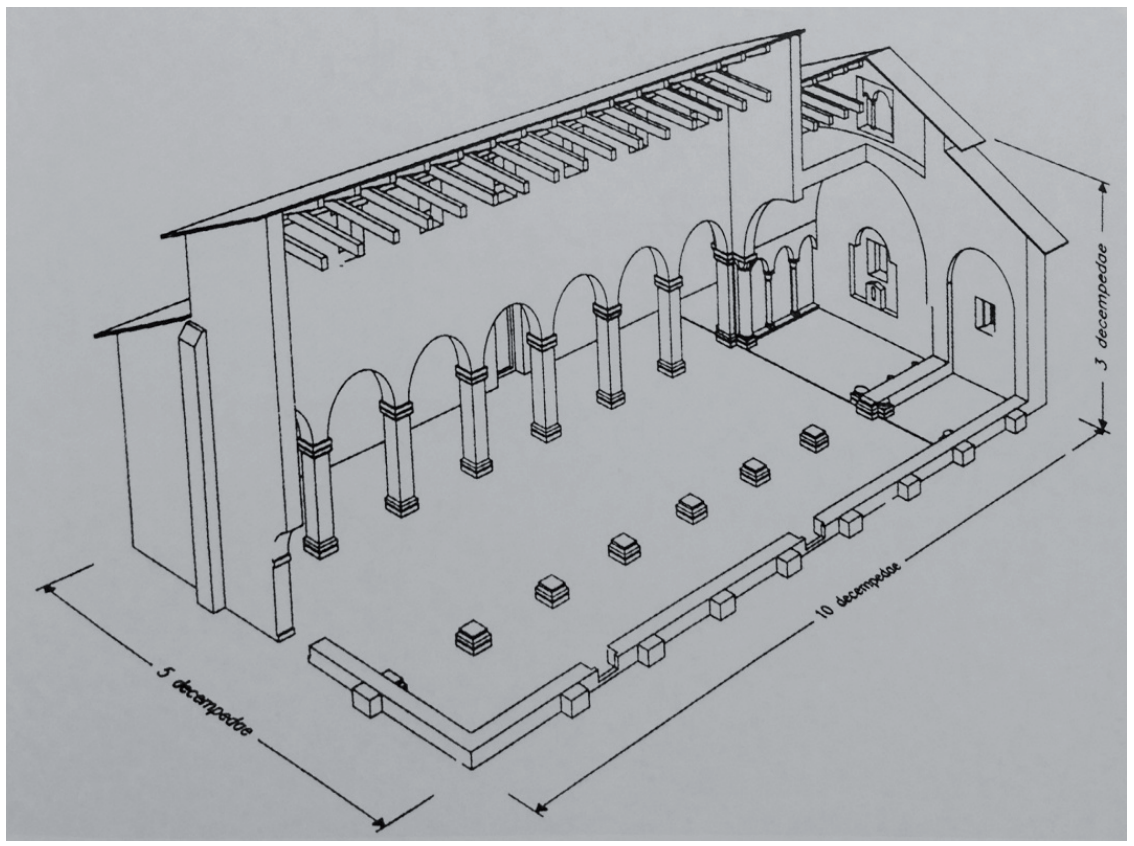

Fig. 3. Reconstrucción ideal de Santa María del Rey Casto, según Lorenzo Arias (Enciclopedia del prerrománico en Asturias, vol. II, p. 535). 

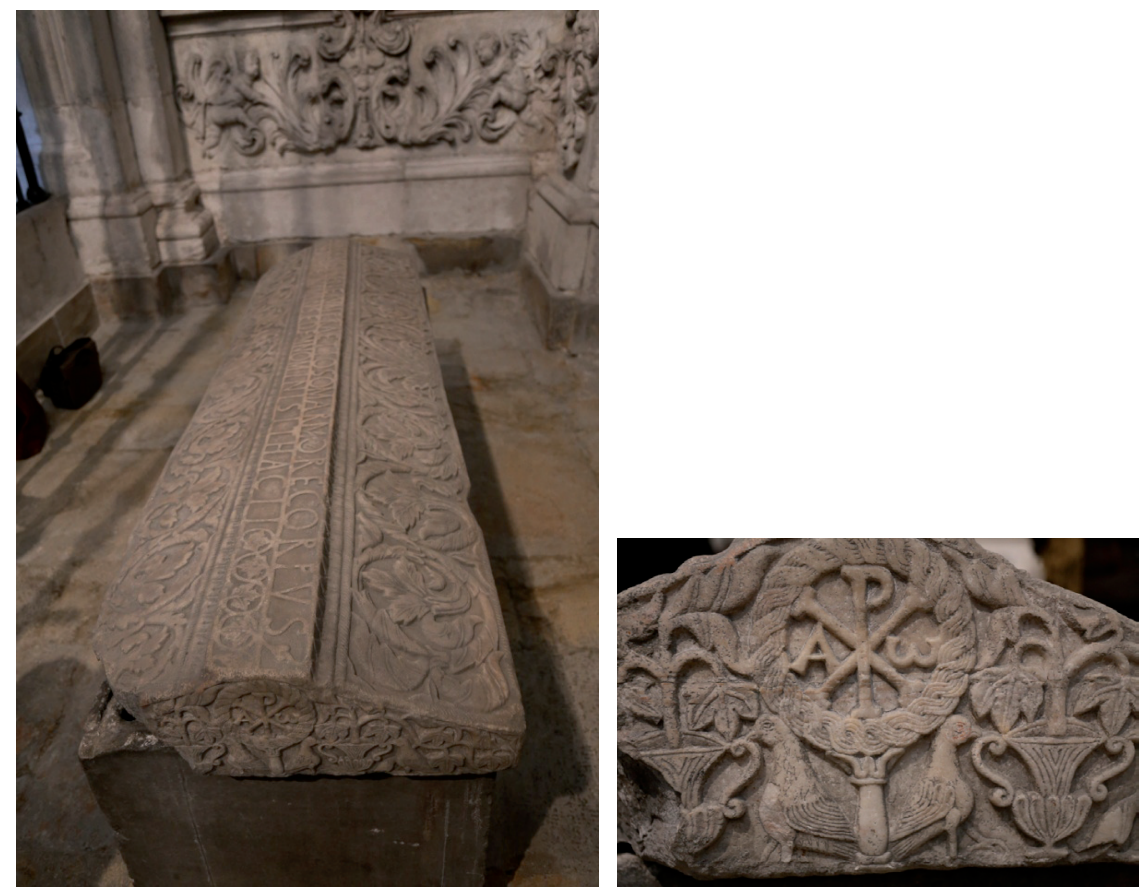

Figs. 4 y 5 (detalle). Sarcófago de Ithacio. Panteón Real. Fotografía: Begoña Torre Miguel. 